\title{
Pattern of lung volumes in patients with sighing breathing
}

Gabriel Aljadeff, Morico Molho, Ido Katz, Shlomo Benzaray, Zippy Yemini, Robert J Shiner

\begin{abstract}
Background-Sighing breathing is observed in subjects suffering from anxiety with no apparent organic disease.

Methods-Lung volumes and expiratory flow rates were measured in 12 patients with a sighing pattern of breathing and in 10 normal subjects matched for age, gender, and anthropometric data. In both groups the measurements were made by spirographic and plethysmographic techniques. In normal subjects functional residual capacity (FRC) and residual volume (RV) were measured during normal breathing and again during simulated sighing breathing to exclude technical artifacts resulting from hyperventilation during measurement by the helium closed circuit method.

Results-Patients with a sighing pattern of breathing had a normal total lung capacity (TLC) but significantly different partitioning of lung compartments compared with normal subjects. The vital capacity (VC) was lower when measured by both spirographic and plethysmographic methods and RV was higher. The forced expiratory volume in one second $\left(F_{1}\right)$ was also lower in patients with sighing breathing. The $\mathrm{FEV}_{1} / \mathrm{VC}$ and the maximal expiratory flow rates at $50 \%$ and at $25 \%$ of the forced vital capacity $\left(\vec{\nabla}_{50}\right.$ and $\left.\vec{V}_{25}\right)$ were normal and similar in both groups. In normal subjects there were no differences in $R V$ when measured during quiet or simulated sighing breathing.

Conclusions-Subjects with sighing breathing have a normal TLC with a higher RV and lower VC than normal subjects. There was no obvious physiological or anatomical explanation for this pattern.
\end{abstract}

(Thorax 1993;48:809-811)

Many patients are referred for specialist evaluation of shortness of breath. Not infrequently a sighing pattern of breathing is observed when spirography is recorded on graph paper. Sighing breathing, otherwise known as hyperventilation syndrome, ${ }^{1}$ psychogenic hyperventilation, ${ }^{2}$ or behavioural breathlessness, ${ }^{3}$ is characterised by highly irregular breathing punctuated by deep periodic inspirations (fig). The majority of

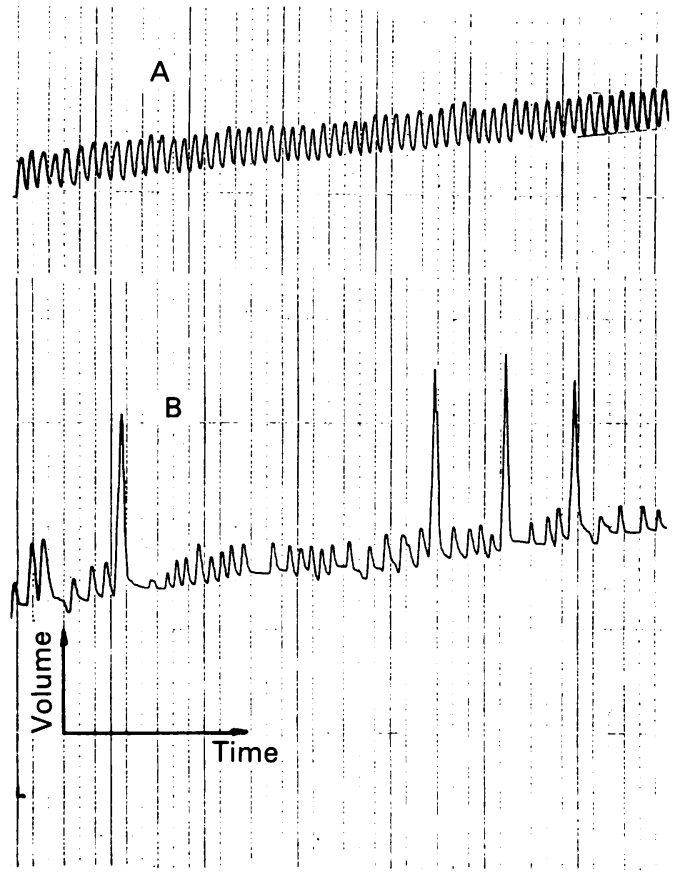

Normal respiration pattern on spirometry $(A)$ and sighing breathing pattern (B).

patients describe their shortness of breath as an inability to "get enough air into their lungs". Most cases suffer from some form of psychoneurosis $^{3}$ with no apparent organic disease and the diagnosis is easily made on the basis of symptoms and signs. ${ }^{1-10}$ Typically, there is no exertional dyspnoea, and these subjects usually feel better during exercise and do not benefit from bronchodilator therapy. With the exception of hyperventilation and hypocapnoea, no other clinical abnormalities have been described in these patients. ${ }^{37}$ In our experience a large RV is frequently present in the absence of lung disease or thoracic cage abnormalities. In one study $\mathrm{RV}$ was abnormally high in five of 21 patients but no reference was made to the significance of this. ${ }^{3}$

We have undertaken a study to verify our observation with both spirographic and plethysmographic measurements in patients complaining of sighing breathing and in normal subjects during normal respiration and during simulated sighing breathing.

\section{Methods}

Lung volumes and maximal expiratory flow rates were measured in 12 patients with a 
sighing pattern of breathing and in 10 healthy volunteers matched for age, gender, and anthropometric values. All subjects underwent careful clinical and radiological examination to exclude lung, heart or neuromuscular diseases, thoracic deformities, obesity, smoking habits, atopy, recent respiratory tract infection, or any other condition that could interfere with normal respiratory functions. The radiological examination of normal subjects was part of the check up. Approval of the ethics committee was not sought as we felt that the tests were consistent with our usual evaluation of patients with dyspnoea. Informed consent was obtained from all subjects. No formal psychiatric assessment was undertaken.

A consistent history, the spirographic recordings, and a low mean (SD) end tidal $\mathrm{PCO}_{2}$ of $4.40(0.27) \mathrm{kPa}$ confirmed the sighing pattern of breathing.

Lung volumes were assessed by both spirographic (with helium closed circuit technique for FRC) and plethysmographic methods. In normal subjects FRC was measured during quiet breathing and during artificial sighing breathing. Subjects were asked to take one deep breath every 30 seconds, except during the last minute, after which they were requested to breathe normally to avoid changes in the expiratory level. This double checking was to avoid spirometric pitfalls; we suspected that sighing during measurements by the helium closed circuit technique could lead to artificially high values of FRC. The amount of helium absorbed during this technique is generally minimal and depends on the duration of the test and the weight of the subject [helium absorbed $(\mathrm{ml})=\mathrm{W}(\mathrm{kg}) / 3 \times$ $\mathrm{t}(\mathrm{min})]$. This volume was subtracted from the observed FRC value. The time correction factor, which is only one component of ventilation, may be insufficient to avoid inexact measurement in the presence of hyperventilation or sighing. Deep breaths recruit more respiratory units and some helium can be absorbed or trapped in a larger ventilated area. Spirographic records frequently show an upward movement of the expiratory level

Mean (SD) anthropometric data, spirographic and plethysmographic measurements (\% predicted) in normal subjects and patients with sighing breathing.

\begin{tabular}{|c|c|c|c|c|}
\hline & \multicolumn{2}{|l|}{ Normal subjects } & \multicolumn{2}{|c|}{ Sighing patients } \\
\hline $\begin{array}{l}\text { Age (y) } \\
\text { M:F } \\
\text { Height }(\mathrm{cm}) \\
{\text { Body surface area }\left(\mathrm{m}^{2}\right)}_{\text {FEV }_{1}} \\
\text { FEV }_{1} / \mathrm{VC} \\
\mathrm{V}_{50} \\
\mathrm{~V}_{25} \\
\text { VC } \\
\text { RV } \\
\text { TLC } \\
\text { FRC }\end{array}$ & $\begin{array}{l}36(6) \\
8: 2 \\
173(8) \\
1 \cdot 85(0 \cdot 02) \\
109(12) \\
105(6) \\
105(29) \\
99(28) \\
\text { Spirographic } \\
105(12) \\
95(12) \\
102(9) \\
109(11)\end{array}$ & $\begin{array}{l}\text { Plethysmographic } \\
108(12) \\
104(23) \\
107(10) \\
119(16)\end{array}$ & $\begin{array}{l}33(12) \\
8: 4 \\
170(11) \\
1 \cdot 85(0 \cdot 02) \\
97(9) \\
104(5) \\
96(17) \\
96(17) \\
\text { Spirographic } \\
93(10)^{\star} \\
123(21)^{\star} \\
100(12) \\
107(17)\end{array}$ & $\begin{array}{l}\text { Plethysmographic } \\
98(13)^{\star \star} \\
138(37)^{\star} \\
108(15) \\
121(17)\end{array}$ \\
\hline
\end{tabular}

$\mathrm{FEV}_{1}$ - forced expiratory volume in one second; VC-vital capacity; RV-residual volume; TLC - total lung capacity; FRC - functional residual capacity; $\nabla_{50}$-maximal expiratory flow rate at $50 \%$ of forced VC; $V_{25}$-maximal expiratory flow rate at $25 \%$ of forced VC. ${ }^{\star} \mathrm{p}<0.01 ;{ }^{\star \star} \mathrm{p}<0.05$. after deep breaths which may artificially increase FRC.

The measurements were made during mid morning in the sitting position and in the same sequence for all subjects. A computerised water spirometer (Godard-Statham BV type 15422) and a computerised constant volume plethysmograph (Jaeger Master Lab type $\mathrm{ML} / \mathrm{B}$ ) were used. None of the subjects were taking any drugs at the time of the study.

The thoracic gas volume was measured five times and an average value was calculated. The flow-volume curves were recorded with the same equipment, the flow and volume changes being measured at the mouth, and the best curve was automatically integrated from at least three manoeuvres. The observed values were compared with the predicted normal values in this laboratory. ${ }^{11}$

\section{STATISTICAL ANALYSIS}

Normal distribution goodness of fit test was performed on each variable in each group. Since the variables were normally distributed at the $95 \%$ confidence level, the hypothesis test of the means was used to determine significant differences in the measurements between the two groups. The possibility of a type II statistical error (as a small number of subjects were involved) is unlikely in view of the high $a(>0.05)$ and the small variability of the population.

Regression analysis of spirometric and plethysmographic measurements was used to determine the correlation between them.

\section{Results}

There were no significant differences in age sex distribution, and anthropometric data between the two groups. The lung volumes measured by both methods were within normal values. However, all the patients had a significantly lower VC ( $p<0.01$ by spirography and $\mathrm{p}<0.05$ by plethysmography) and a significantly higher RV $(p<0.01$ by both methods) than the normal subjects, while TLC and FRC were similar in both groups There were no differences between spirographic and plethysmographic measurements. The forced expiratory volume in one second $\left(F V_{1}\right)$ was significantly lower in the patien group ( $\mathrm{p}<0.01$ ) but the $\mathrm{FEV}_{1} / \mathrm{VC}$ ratio and maximal flow rates at $50 \%$ and $25 \%$ of forced VC $\left(\nabla \max _{50}\right.$ and $\left.V \max _{25}\right)$ were similar in both groups (table).

In the normal subjects RV and FRC were similar with normal breathing and with artificial sighing when measured with the helium closed circuit technique.

\section{Discussion}

Our results provide convincing evidence that patients with a sighing breathing pattern have different partitioning of lung volumes from normal subjects, having a smaller VC and larger RV, but a similar TLC and FRC. The fact that there were no differences in the 
measurements of FRC during normal and sighing breathing in the normal subjects proves that this is not an artifact.

The different partitioning of lung volumes in the two groups can be explained by differences in the shape and compliance of the thoracic cage. ${ }^{12}$ Although we cannot entirely exclude this possibility as chest wall compliance measurements were not performed, thoracic abnormalities were not noted and there were no differences in age, sex distribution, and anthropometric data between the two groups. Anatomical reasons can hardly explain the respiratory symptomatology which is characterised by periodic episodes and not by constant symptoms aggravated by exercise.

The normal expiratory flow rates in the patients exclude air trapping resulting from airway obstruction. Their lower FEV 1 is related to the lower $\mathrm{VC}$ since the $\mathrm{FEV}_{1} / \mathrm{VC}$ ratio is normal. Moreover, if airflow limitation is the cause of air trapping and of the sighing breathing pattern, remission of symptoms should result in correction of the physiological abnormality.

In a study of patients with chronic hyperventilation five of 21 patients had an increased RV yet bronchial responsiveness (as determined by histamine challenge) was not increased. ${ }^{10}$ An increase in $\mathrm{RV}$ indicates that the lung is still hyperinflated after maximal expiratory effort. Reasons for an increased
RV include changes in the thoracic cage, respiratory muscles, or in lung tissues, ${ }^{12}$ but there was no evidence for any of these in our patients although they were not specifically sought.

We conclude that the pattern of lung volumes in patients with sighing breathing is characterised by a lower VC and a higher RV than in normal subjects. No obvious physiological or anatomical explanation for this pattern could be found.

1 Rice RL. Symptom patterns of the hyperventilation syndrome. $A m$ f Med 1950;8:691.

2 Fraser RG, Pare' JAPP. Diagnosis of diseases of the chest. 2nd edn, vol 3. Philadelphia: Saunders, 1979: 1944-5.

3 Howell JBL. Behavioral breathlessness. Thorax 1990;45: 287-92.

4 Mechanic D. Social psychologic factors affecting the presentation of body complaints. $N$ Engl f Med 1972; 286:1132-9.

$5 \mathrm{Ker}$ WJ. Some physical phenomena associated with the anxiety states and their relation to hyperventilation. Ann Intern Med 1937;2:962.

6 Comroe JH. Physiology of respiration. 2nd edn. Chicago: Year Book, 1974:232.

7 Lum JR. Hyperventilation and anxiety states. $\mathcal{F} R$ Soc Med 1981;74:1-4.

8 Lum JR. Hyperventilation syndromes in medicine and psychiatry: a review. $\mathcal{F} R$ Soc $M e d$ 1987;80:229-31.

9 Magarian GJ. Hyperventilation syndromes: infrequently recognized common expressions of anxiety and stress. Medicine 1982;61:219-36.

10 Bass C, Gardner WN. Respiratory and psychiatric abnormalities in chronic symptomatic hyperventilation. $B M \mathcal{\jmath}$ 1985;290:1387-90.

11 Qanjer PH (ed). Standardized lung function testing. Bull Eur Physiopathol Respir 1983;19(Suppl 5):1-91.

12 Comroe JH. Physiology of respiration. 2nd edn. Chicago: Year Book, 1974:172-7. 